Research Article

\title{
Effectiveness of a Planned Teaching Programme to Educate Adolescent Girls in the Avoidance and Dealing with Iron Deficiency Anaemia in a Selected School of Bilaspur District
}

\author{
Shailvina D Masih', Linson $\mathrm{CC}^{2}$ \\ ${ }^{1} \mathrm{PhD}$ Scholar, Dr Sarvapalli Radhakrishnan (SRK) University, Bhopal (M.P.), India. \\ 2JOSCO, Mangalore. \\ DOI: https://doi.org/10.24321/2348.2141.202004
}

\section{I $\quad \mathbf{N} \quad \mathbf{F} \quad \mathbf{O}$}

\section{Corresponding Author:}

Shailvina D Masih, Dr Sarvapalli Radhakrishnan (SRK) University, Bhopal (M.P.), India.

E-mail Id:

masihshailvina@gmail.com

Orcid Id:

https://orcid.org/0000-0002-9177-8680

How to cite this article:

Masih SD, Linson CC. Effectiveness of a Planned

Teaching Programme to Educate Adolescent Girls in the Avoidance and Dealing with Iron Deficiency Anaemia in a Selected School of Bilaspur District. Trends Nurs Adm Edu 2020; 9(2): 11-16.

Date of Submission: 2020-12-12

Date of Acceptance: 2020-12-27

\section{$\begin{array}{llllllll}\mathbf{A} & \mathbf{B} & \mathbf{S} & \mathbf{T} & \mathbf{R} & \mathbf{A} & \mathbf{C} & \mathbf{T}\end{array}$}

Background: Nowadays young adolescents face many problems because of their lifestyle modifications such as eating junk foods, fast foods, snacking, and skipping meals.

Some adolescents are undernourished due to a lack of awareness regarding dietary iron and poor socioeconomic status. These are quite common among urban adolescent girls.

Iron deficiency anaemia is the most prevalent nutritional disorder in the world today. Iron is a necessary mineral for body function and good health. A lack of iron in the blood can lead to iron deficiency anaemia, which is a very common nutritional deficiency among children and adolescents.

Objective: This study is aimed to analyse the effectiveness of a planned teaching programme to educate adolescent girls in the prevention and management of iron deficiency anaemia in a selected school of Bilaspur district.

Method: Convenient sampling technique and structured questionnaire were used in the study.

Result and Conclusion: The findings revealed that about 38\% of the adolescent girls belonged to the age group of $14.1-15$ years, $85 \%$ belonged to the Hindu religion, $48 \%$ had family income $>30,000$ INR, $63 \%$ belonged to nuclear families, fathers of $60 \%$ of the adolescent girls were government employees, mothers of $48 \%$ of the adolescent girls were housewives, $78 \%$ of the adolescent girls belonged to urban areas, and $48 \%$ of the adolescent girls had got the information through mass media. The distribution of the adolescent girls among the 9th, 10th, 11th, and 12th standards was found to be equal ( $25 \%$ each).

The assessment of the overall pre-test knowledge level of adolescent girls shows that $3 \%$ had good knowledge, $86 \%$ had average knowledge, and $11 \%$ had below-average knowledge.

Keywords: Assess Effectiveness, Planned Teaching Programme, Knowledge, Iron Deficiency Anaemia 


\section{Introduction}

"Adolescent would be the Best Investment for Future"

Sundarlal

Health is a basic human right, and it is at the heart of the idea of quality of life. The second decade of adulthood is known as adolescence. Adolescents account for more than a quarter of India's population. Adolescence starts when secondary sex features emerge, and finishes when the individual's physical development is complete and he or she is socially mature and capable of contributing to society.

Adolescents belong to the age group of 12 to 18 years. Girls begin to menstruate at this age. The girl should weigh approximately 42-64 kg and should be approximately 155$169 \mathrm{~cm}$ tall. Total nutrient requirements increase during adolescence to support a period of dramatic growth and development. Eating the right food at the right time will prevent nutritional deficiencies especially iron deficiency disorders.

According to the World Health Organisation (WHO), the haemoglobin level should be $12 \mathrm{~g} / \mathrm{dl}$ for adolescent girls. A haemoglobin level of less than $12 \mathrm{~g} / \mathrm{dl}$ is considered iron deficiency anaemia. WHO graded the haemoglobin level of $10 \mathrm{~g} / \mathrm{dl}$ as mild iron deficiency anaemia, haemoglobin between $7 \mathrm{~g} / \mathrm{dl}$ to $10 \mathrm{~g} / \mathrm{dl}$ as moderate iron deficiency anaemia, and haemoglobin less than $7 \mathrm{~g} / \mathrm{dl}$ as severe iron deficiency anaemia.

To avoid being a part of these statistics, the best solution is to take appropriate preventive measures. There are three possible interventions for the prevention of anaemia. These include dietary diversification, food fortification, and individual supplementation. Dietary diversification involves the promotion of a diet with a wider variety of iron-containing food and encouraging families with deficient iron intake to eat meat, fish, or poultry; whole or enriched grain; and foods high in ascorbic acid.

\section{Need for the Study}

Iron deficiency anaemia is one of the most prevalent nutritional deficiencies in the world, especially among adolescent girls. Adolescents gain $20 \%$ of the adult weight and $30 \%$ of the adult height in the adolescent period itself.

A high prevalence of iron deficiency anaemia reflects their poor status of nutrition because of their rapid growth combined with poor eating habits and menstruation. The World Health Report of World Health Organization (WHO) states that the worldwide mortality rate of iron deficiency anaemia was $60,404,000$ in 2005. National Family Health survey in 2006 showed that $56 \%$ of adolescent girls were anaemic in India.

Based on this information, the researcher feels that it is important to prevent iron deficiency anaemia among adolescent girls.

\section{Objectives of the Study}

- To analyse the effectiveness of a planned teaching programme to educate adolescent girls in the prevention and management of iron-deficiency anaemia in a selected school of Bilaspur district

- To find the association between pre-test knowledge score and selected demographic variables

\section{Hypothesis}

The hypotheses will be tested at a 0.05 level of significance.

$\mathbf{H}_{0}$ : There will be no significant difference between pre-test and post-test scores on the knowledge of adolescent girls regarding prevention and management of iron deficiency anaemia in a selected English medium school in Bilaspur.

$\mathbf{H}_{1}$ : The mean post-test knowledge score on knowledge of adolescent girls regarding prevention and management of iron deficiency anaemia in a selected English medium school in Bilaspur will be significantly higher than their mean pre-test knowledge score.

$\mathbf{H}_{2}$ : There is a significant association of pre-test knowledge scores of adolescent girls regarding prevention and management of iron deficiency anaemia in a selected English medium school in Bilaspur with their selected demographic variables.

\section{Assumptions}

- The adolescent girls will have adequate knowledge and positive attitude regarding the prevention of iron deficiency anaemia

- The adolescent girls will follow the preventive measures for iron deficiency anaemia such as increased dietary iron intake, maintaining personal hygiene, periodic deworming, periodic screening of haemoglobin, avoiding Junk foods and fast foods and regular intake of weekly iron supplementation

\section{Material and Methodology}

\section{Research Approach}

Quantitative research approach

\section{Research Design}

The design opted for this study is pre-experimental in nature.

\section{Setting}

The study was conducted in a selected school in Bilaspur and written permission was obtained from the concerned authorities and samples prior to the study.

\section{Duration of the Study}

The study was conducted from 15/09/2020 to 15/10/2020. 


\section{Population}

Accessible Population: All the selected adolescent girls who meet the inclusion criteria and are studying in selected schools in Bilaspur.

Target Population: Adolescent girls who are studying in a selected English medium school in Bilaspur.

\section{Criteria for Selection of Samples}

\section{Inclusion Criteria}

- Adolescent girls who belonged to the age group of 13 to 17 years

- Adolescent girls who were willing to participate in this study

\section{Exclusion Criteria}

- Adolescent boys were excluded from the study

- Adolescent girls who were absent at the time of the study

- Adolescent girls who were sick at the time of data collection

- Adolescent girls who were not present at the time of data collection

\section{Sample Selection}

Sample Size: The sample size of the study was 100 adolescent girls.

Sample Technique: The research study was conducted by non-probability purposive sampling technique.

\section{Variables}

\section{Independent Variable}

Planned teaching programme for adolescent girls in the selected school regarding prevention and management of iron deficiency anaemia.

\section{Dependent Variable}

Knowledge of adolescent girls regarding avoidance and dealing with iron deficiency anaemia in the selected school at Bilaspur.

\section{Procedure for Data Collection}

The data were collected from adolescent girls regarding the prevention and management of iron deficiency anaemia in the selected school in Bilaspur. Before the collection of data, formal written consent was obtained from adolescent girls.

\section{Description of the Tool Used}

The investigator has prepared a structured knowledge questionnaire to assess the knowledge of the sample on prevention and treatment of iron deficiency anaemia. The tool was divided into two sections as follows:

\section{Section: I}

This tool was constructed by the investigator. It contained 9 items for obtaining information regarding age, standard of study, religion, family income, type of family, occupation of father and mother, resident area, and source of information of samples.

\section{Section: II}

The structured knowledge questionnaire consisted of multiple-choice items and each item carried one mark. Blueprint was prepared according to the content area as well as the level of cognitive domain, knowledge, comprehension, and application. Out of 26 items, 15 (58\%) fall into knowledge aspects, 7 (27\%) fall into comprehension whereas 4 (15\%) belong to application aspects.

\section{Result}

Section A: Demographic data were analysed using frequency and percentage as follows.

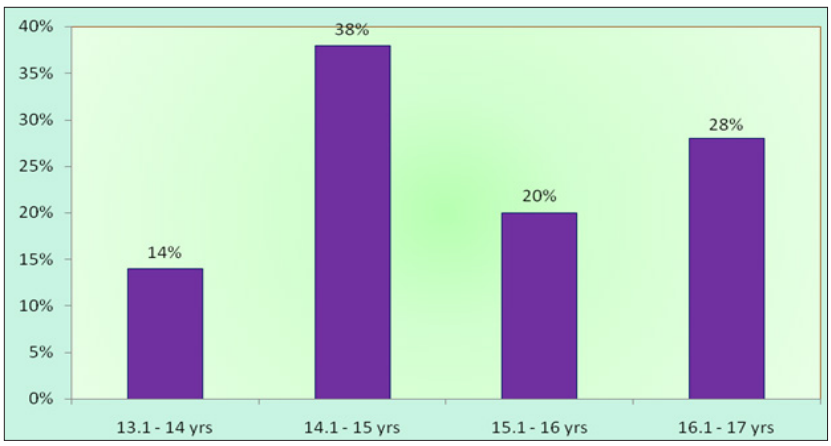

Figure I.Frequency and Percentage Distribution according to Age Group



Figure 2.Frequency and Percentage Distribution according to the Educational Standard



Figure 3.Frequency and Percentage Distribution according to Religion 




Figure 4.Frequency and Percentage Distribution according to Family Income

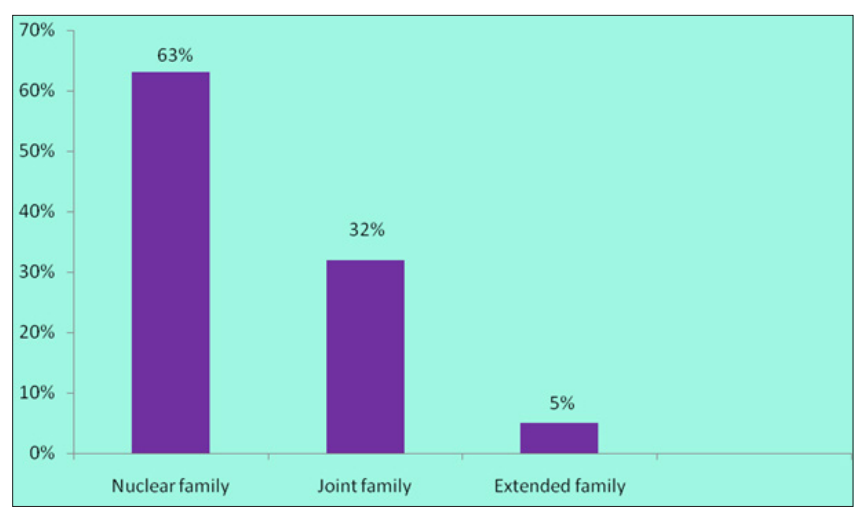

Figure 5.Distribution of Subject according to the Type of Family

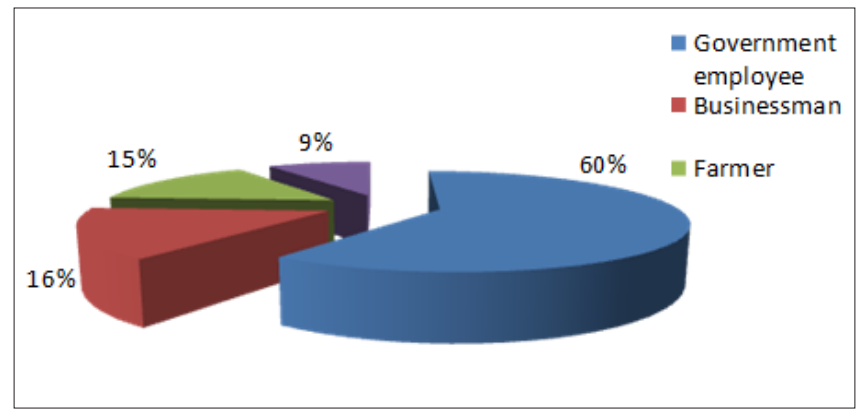

Figure 6.Distribution of Subjects according to the Occupation of Father

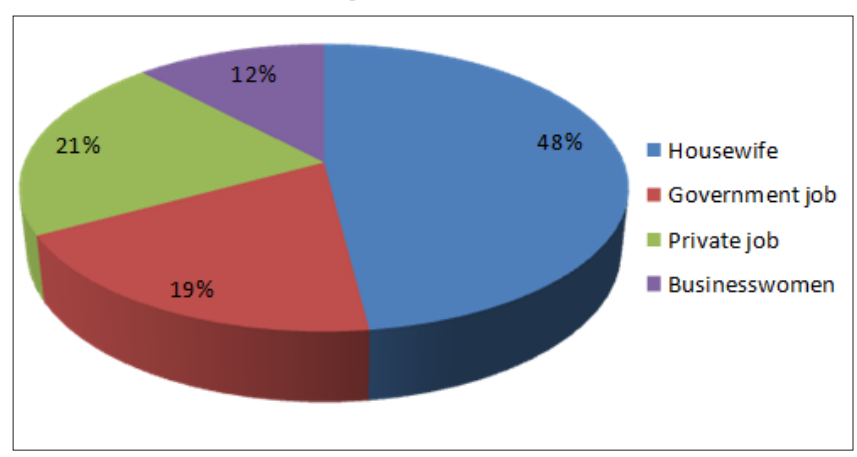

Figure 7.Distribution of Subjects according to the Occupation of Mother



Figure 8.Distribution of Subjects according to the Area of Residence

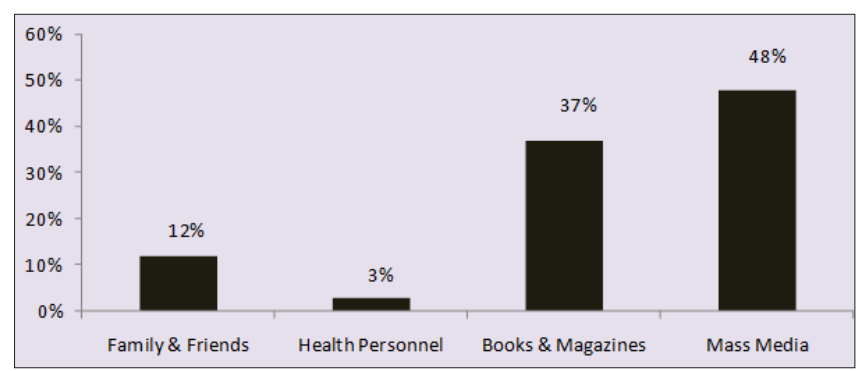

Figure 9.Previous Sources of Information

Section B: Knowledge score between pre-test \& posttest mean, mean percentage, and standard deviation was compared as follows.

Table I.Mean, Mean percentage, and Standard Deviation of the Pre-test and Post-test Knowledge Scores

\begin{tabular}{|c|c|c|c|c|}
\hline $\begin{array}{c}\text { S. } \\
\text { No. }\end{array}$ & Test & $\begin{array}{c}\text { Total } \\
\text { Mean }\end{array}$ & $\begin{array}{c}\text { Mean } \\
\text { Percentage }\end{array}$ & $\begin{array}{c}\text { Standard } \\
\text { Deviation }\end{array}$ \\
\hline 1. & Pre-test & 14.76 & 49.02 & \pm 3.33 \\
\hline 2. & Post-test & 22.01 & 74.03 & \pm 4.15 \\
\hline
\end{tabular}

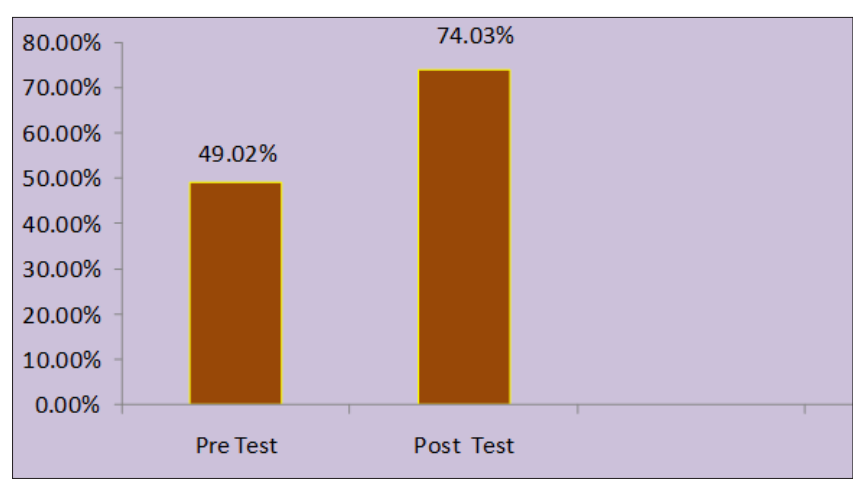

Figure 10.Analysis of Pre-test and Post-test Knowledge Scores 
Section C: Criteria wise analysis of pre-test and post-test knowledge scores was done by frequency and percentage.

Table 2.Analysis of Pre-test and Post-test Knowledge Scores by Frequency and Percentage

\begin{tabular}{|c|c|c|c|c|c|}
\hline \multirow{2}{*}{ S. } & \multirow{2}{*}{$\begin{array}{c}\text { Know- } \\
\text { No. }\end{array}$} & \multicolumn{2}{|c|}{ Pre-test } & \multicolumn{2}{|c|}{ Post-test } \\
\cline { 3 - 6 } & Score & $\begin{array}{c}\text { Freq- } \\
\text { uency }\end{array}$ & $\begin{array}{c}\text { Perc- } \\
\text { entage }\end{array}$ & & \\
\hline 1. & Good & 03 & 3 & 1. & Good \\
\hline 2. & Average & 86 & 86 & 2. & Average \\
\hline 3. & $\begin{array}{c}\text { Below } \\
\text { Average }\end{array}$ & 11 & 11 & 3. & $\begin{array}{c}\text { Below } \\
\text { Average }\end{array}$ \\
\hline & Total & 100 & 100 & & Total \\
\hline
\end{tabular}

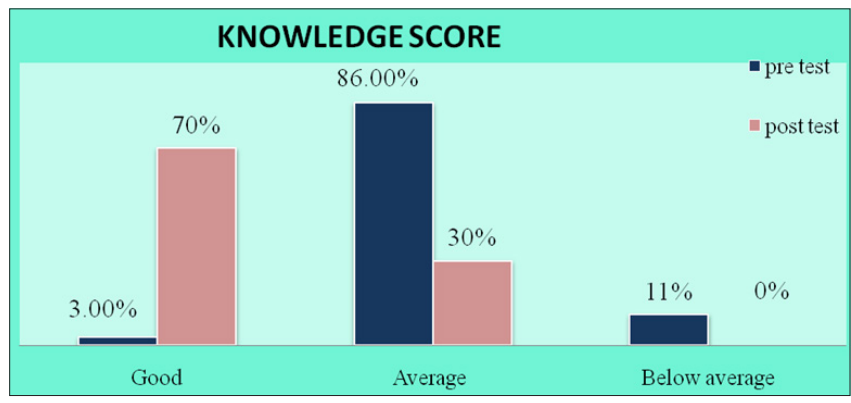

Figure I I.Comparison of Pre-test and Post-test Knowledge Scores

\section{Assessment of Overall Pre-test \& Post-test Knowledge Score}

The assessment of the overall pre-test knowledge level of adolescent girls shows that 3\% have good knowledge, $86 \%$ have average knowledge, and $11 \%$ have below-average knowledge.

The assessment of the overall post-test knowledge level of adolescent girls shows that $70 \%$ have good knowledge, $30 \%$ have average knowledge, and $0 \%$ have below-average knowledge.

Table 3, represents that there is a highly significant difference between pre-test and post-test knowledge scores as the calculated t-value of 14.32, and D.F. (99) is greater than the table value (1.301) at 0.05 level of significance.

\section{Discussion}

This chapter discusses in detail the findings of the study interpreted from the analysis. The findings of the study are discussed in relation to the objectives, need for the study, and related literature of the study.

Characteristics of the Selected Demographic Variables of the Sample

1. $38 \%$ of the adolescent girls belonged to the age group of 14.1-15 years.

2. There was an equal distribution of adolescent girls among the 9th, 10th, 11th, and 12 th standards (25\% each).

3. $85 \%$ of the adolescent girls belonged to the Hindu religion.

4. $48 \%$ of the adolescent girls had a family income $>$ 30,000 INR per month.

5. $63 \%$ of the adolescent girls belonged to nuclear families.

6. The fathers of $60 \%$ of the adolescent girls were government employees.

7. The mothers of $48 \%$ of the adolescent girls were housewives.

8. $78 \%$ of the adolescent girl belonged to urban areas.

9. $48 \%$ of the adolescent girls had got the information through mass media.

\section{Assessment of Overall Pre-test Knowledge Score of Adolescent Girls}

The assessment of the overall pre-test knowledge level of adolescent girls showed that 3\% have good knowledge, $86 \%$ had average knowledge, and $11 \%$ had below-average knowledge.

\section{Assessment of Overall Post-test Knowledge Score of Adolescent Girls}

The assessment of the overall post-test knowledge level of adolescent girls showed that $70 \%$ of the adolescent girls had good knowledge, 30\% had average knowledge, and $0 \%$ had below-average knowledge.

This concludes that $\mathrm{H}_{1}$ is accepted as the mean post-test knowledge score on knowledge of adolescent girls regarding

Table 3.Paired ' $t$ ' Test for Assessing Significant Difference between Pre-test and Post-test Knowledge Scores

$(N=100)$

\begin{tabular}{|c|c|c|c|c|c|c|c|}
\hline "t" Test & Mean & $\begin{array}{l}\text { Standard } \\
\text { Deviation }\end{array}$ & D.F. & $\begin{array}{c}\text { Calculated ' } \mathrm{t} \text { ' } \\
\text { Value }\end{array}$ & $\begin{array}{c}\text { Table 't' } \\
\text { Value }\end{array}$ & $\begin{array}{c}\text { Standard } \\
\text { Error }\end{array}$ & Significance \\
\hline Pre-test & 14.76 & \pm 3.33 & \multirow{2}{*}{99} & \multirow{2}{*}{14.32} & \multirow{2}{*}{2.00} & \multirow{2}{*}{0.52} & \multirow{2}{*}{$\begin{array}{l}\text { Highly } \\
\text { significant }\end{array}$} \\
\hline Post-test & 22.21 & \pm 4.15 & & & & & \\
\hline
\end{tabular}


prevention and management of iron deficiency anaemia in a selected English medium school in Bilaspur was significantly higher than their mean pre-test knowledge score.

\section{Association of Pre-test and Post-test Knowledge Score of Adolescent Girls}

There is a highly significant difference between the pre-test and post-test knowledge scores as the calculated t-value of 14.32 , and D.F. (99) is greater than the table value (1.301) at a 0.05 level of significance.

\section{Conclusion}

The findings indicated that the planned teaching programme prepared by the investigator was effective in enhancing the knowledge of the samples towards prevention and management of iron deficiency anaemia.

\section{Limitations of the Study}

This study was delimited to:

- 100 adolescent girls in the selected English medium school in Bilaspur

- Data was collected in a period of 4 to 6 weeks

- Samples were restricted to the selected English medium school in Bilaspur

\section{Recommendation}

The following recommendations are made on the basis of the findings of the present study:

1. A similar study can be replicated on a large sample covering the different states of India so that the findings can be generalized for a large population.

2. A similar study can be conducted on antenatal women or children.

3. A study can be conducted to assess the knowledge of antenatal women regarding iron deficiency anaemia in selected rural and urban areas of Bilaspur.

4. A comparative study can be conducted in order to compare the knowledge regarding the prevention and management of iron deficiency anaemia between the experimental group and control group of samples.

5. A study can be conducted using other teaching strategies.

6. A survey can be conducted on assessing the knowledge of adolescent girls regarding prevention and management of iron deficiency anaemia with a view to develop an information booklet.

7. A survey can be conducted to assess the iron status of adolescent girls from different schools in Chhattisgarh state.

8. A true experimental study may be carried out to standardize the planned teaching programme.

\section{Conflict of Interest: None}

\section{References}

1. Basavanthappa BT. Nursing research. 1st ed. Bangalore: Jaypee Brothers Publishers; 2003. p. 7.

2. Prateek B, Sharma S. A textbook of nursing research \& statistics. $3^{\text {rd }}$ ed. Jalandhar: S. Vikas \& Company; 2011.

3. Black JM, Hawks JH. Medical surgical nursing, clinical management for positive outcome. 7th ed. Vol. 2. India: Elsevier Saunders Publication; 2005.

4. Curley MAQ, Moloney-Harmon PA. Critical care nursing. 2nd ed. Philadelphia: W. B. Saunders Company; 2001.

5. Tortora GJ, Grabowski SR. Principles of anatomy and physiology. 10 $0^{\text {th }}$ ed. USA: John Wiley \& Sons. Inc; 2003.

6. Harkreader H. Fundamentals of nursing, caring \& clinical judgment. 2nd ed. Missouri: Saunders Publication; 2004.

7. International Council of Nurses. Notes on nursing, a guide for today's caregiver. Geneva: Bailliere Tindall Elsevier; 2009.

8. Barbara K. Fundamentals of nursing: concepts, process $\&$ practice. $7^{\text {th }}$ ed. Saunders Publication: New Delhi; 2005.

9. Lewis SM, Heitkemper MM, Dirksen SR. Medical surgical nursing, assessment and management of clinical problems. $7^{\text {th }}$ ed. Philadelphia: Mosby Publishers; 2004.

10. Long BC, Phipps WJ, Cassmeyer VL. Medical surgical nursing, a nursing process approach. 3rd ed. USA: Mosby's Publication; 1993.

11. Kumari N. A textbook of management of nursing services and education. Jalandhar: S. Vikas \& Company; 2009.

12. Sundar Rao PSS, Richard J. Introduction to biostatistics and research methods. 4th ed. New Delhi: PHI Learning Private Limited; 2009.

13. Polite DF, Beck CT. Nursing research: generating and assessing evidence for nursing practice. 8th ed. New Delhi: Wolters Kluwer Pvt Ltd; 2008. 